\title{
O uso de recursos de tecnologia assistiva por crianças com deficiência física na escola regular: a percepçáo dos professores ${ }^{1}$
}

\author{
Ana Cristina de Jesus Alves ${ }^{\mathrm{a}, \mathrm{b}}$, Thelma Simóes Matsukura ${ }^{\mathrm{c}, \mathrm{d}}$ \\ aDoutoranda pelo Programa de Pós-graduação em Educação Especial, \\ Centro de Educação e Ciências Humanas, Universidade Federal de São Carlos - UFSCar, São Carlos, SP, Brasil

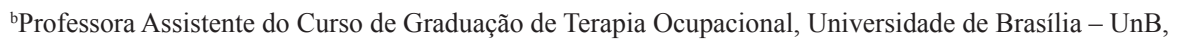 \\ 'Doutora pelo Programa de Pós-graduação em Saúde Mental, \\ Universidade de São Paulo - USP, Ribeirão Preto, SP, Brasil \\ dPrograma de Pós-graduação em Educação Especial, Programa de Pós-graduação em Terapia Ocupacional, \\ Centro de Ciências Biológicas e da Saúde, Universidade Federal de São Carlos - UFSCar, São Carlos, SP, Brasil
}

\begin{abstract}
Resumo: O Censo Escolar realizado no Brasil no ano de 2010 mostrou que o número de deficientes matriculados no ensino regular foi de 702.603. O uso de recursos de tecnologia assistiva no contexto escolar vem sendo indicado para favorecer a execução de tarefas, o acesso aos conteúdos pedagógicos e aos ambientes escolares auxiliando, consequentemente, a aprendizagem dos indivíduos com deficiência. Porém, poucos são os estudos que apontam as repercussões trazidas pelos recursos no processo de escolarização da criança com deficiência física. O objetivo desse estudo foi identificar as contribuições e dificuldades no uso de recursos de tecnologia assistiva no contexto da escolarização no ensino regular do aluno com paralisia cerebral mais comprometido motoramente a partir do ponto de vista do professor. Participaram deste estudo cinco professores de alunos com paralisia cerebral que faziam uso de recurso de tecnologia assistiva na execução de tarefas de escrita e/ou comunicação. Foram realizadas entrevistas semiestruturadas e os dados obtidos foram analisados a partir da técnica do Discurso do Sujeito Coletivo (DSC). Os resultados evidenciaram que os recursos de tecnologia assistiva já estão inseridos na escola regular e que os mesmos trouxeram contribuições ao processo de escolarização da criança com paralisia cerebral em classe comum, porém, estão sendo implementados sem sistematização, acompanhamentos e/ou parcerias. O estudo apontou para a necessidade de considerar as opiniões e necessidades dos principais envolvidos no contexto em que o recurso de tecnologia está inserido.
\end{abstract}

Palavras chave: Equipamentos de Auto-Ajuda, Paralisia Cerebral, Educação Especial, Professor.

\section{The use of assistive technology resources for disabled children in regular schooling: the teachers' perception}

\begin{abstract}
The national School Census revealed that 702,603 disabled people were enrolled in regular education in 2010. The use of assistive technology resources in the school context has been indicated to favor the execution of tasks and the access to educational content and school environments and, consequently, help disabled individuals' learning. However, there are few studies showing the impact of these resources in the education process of children with physical disabilities. The aim of this study was to identify, from the teacher's viewpoint, the contributions and difficulties in the use of technology resources with students with cerebral palsy, focusing on those with severe motor impairment, attending regular education. The study included five teachers of these
\end{abstract}

Autor para correspondência: Ana Cristina de Jesus Alves, Universidade de Brasília, QNN 14 Área Especial, Ceilândia Sul, Brasília, DF, Brasil, e-mail: crisjalves@yahoo.com.br

Recebido em 4/7/2011; Revisão: 21/3/2012; Aceito em 15/5/2012. 
students who were using assistive technology resources in the execution of writing and/or communication assignments. Semi-structured interviews were conducted and data were analyzed following the Collective Subject Discourse (CSD) technique. Results indicated that assistive technology resources are already included in regular schools and that they have brought contributions to the education process of children with cerebral palsy in regular class; nevertheless, they are being implemented without systematization, monitoring and/or partnerships. The study pointed to the need to consider the opinions and requirements of the people involved in the context where the use of technology is inserted.

Keyword: Self-help Devices, Cerebral Palsy, Special Education, Teacher.

\section{Introdução}

O Censo Escolar realizado no Brasil no ano de 2010 mostrou que o número de deficientes matriculados no ensino regular foi de 702.603 (BRASIL, 2011).

A escolarização da criança com deficiência é permeada por diversos fatores, entre eles a necessidade de autonomia do aluno, de cumprimento de metas e da participação do professor, do familiar e da própria criança em relação aos processos que envolvam o cotidiano escolar.

Ao focalizarmos a participação do professor nesse contexto, estudos têm mostrado que suas atitudes e expectativas trazem influências ao processo de escolarização do aluno com deficiência física (BROWNING, 2002; GOMES; BARBOSA, 2006; ARAÚJO; OMOTE, 2005).

Browning (2002), em estudo de revisão de literatura sobre fatores que influenciam o desenvolvimento das aptidóes literárias de crianças com deficiência física, verificou que as prioridades e expectativas estabelecidas pelo professor e pela família em relaçáo à criança com deficiência física e a falta de oportunidades afetaram o desempenho do indivíduo na escola.

Gomes e Barbosa (2006) avaliaram as atitudes do professor quanto à inclusão de alunos com paralisia cerebral e mostraram que, de 68 professores do ensino fundamental, 59\% discordam da prática de inclusão escolar e $17 \%$ referiram conhecer características dos alunos com paralisia cerebral, sendo essas características focadas em aspectos negativos da deficiência. Em relação aos pontos favoráveis à inclusão, o item mais citado foi a socialização, com $67 \%$ das respostas. Este estudo evidenciou também que os participantes que afirmaram conhecer as características da criança com paralisia cerebral tiveram atitudes mais positivas do que os que afirmaram desconhecer. Aqueles docentes que julgaram ser de sua responsabilidade educar um aluno com necessidades educacionais especiais apresentaram atitudes mais positivas.

Já Araújo e Omote (2005) investigaram, através de entrevistas com 97 estudantes do curso de Pedagogia, as suas percepçóes sobre a gravidade da deficiência física e a relação com o contexto escolar em que os alunos devem estar inseridos. Os resultados mostraram que houve a tendência dos participantes em atribuir o grau severo de deficiência física ao contexto escolar especial e a necessidade de recurso adaptado. A descriçáo funcional dos alunos com paralisia cerebral não apresentou influência nas respostas dos participantes.

Diante desses dados, os pesquisadores pontuaram que a percepção de severidade de acometimentos motores não deve constituir um referencial de elegibilidade educacional e que a atribuição de gravidade às deficiências deve apoiar-se na relaçáo do indivíduo com o meio e na sua capacidade de realizar tarefas.

\subsection{A tecnologia assistiva no contexto escolar}

Copley e Ziviani (2004) realizaram um estudo de revisão bibliográfica sobre o uso dos recursos de tecnologia assistiva na escola por crianças com deficiências múltiplas e concluíram que os benefícios trazidos pela tecnologia assistiva vão além de permitir que os usuários executem as tarefas ou as funções que seriam incapazes de realizar de outra maneira. Os recursos são meios de permitir o domínio ou o controle sobre seu ambiente, incluindo o brincar e a independência exploratória realçados nas atividades da vida diária. Os autores mostraram nessa revisão que a promoção da independência foi, dentre os benefícios, o mais frequentemente citado por pais e por professores.

$\mathrm{Na}$ literatura nacional encontram-se várias publicaçôes sobre indicaçóes de recursos às crianças com paralisia cerebral que visam favorecer o desempenho escolar (GODÓI; GALASSO; 
MIOSSO, 2002; SILVA; CASTRO; BRANCO, 2006; SCHINEMER et al., 2007; BRASIL, 2002; MANZINI; DELIBERATO, 2006; BERSCH; PELOSI, 2007).

Nessas publicaçóes, divulgadas pelo Ministério da Educação e Cultura - MEC, o uso de recursos de comunicação alternativa, de materiais e atividades adaptadas, de recursos de adequação postural, computador e o planejamento arquitetônico é apontado como facilitador ao processo de aprendizagem do aluno com deficiência física e contribuinte ao profissional de educação na busca de soluçôes para minimizar limitaçôes funcionais, motoras e sensoriais do aluno com deficiência física (BRASIL, 2011).

Ainda que essas publicaçôes apresentem sugestóes de recursos possíveis ao contexto da inclusão escolar, ao realizar o levantamento bibliográfico utilizando-se os descritores equipamentos de autoajuda e deficiência nas bases de dados Medline, Lilacs e Sciello no período de 2000 a 2010, pouco foi encontrado sobre as repercussóes trazidas pelos recursos no processo de escolarização da criança com deficiência física na realidade nacional.

Diante disso, estudo teve como objetivo identificar as contribuiçôes, dificuldades e o cotidiano implicados no uso de recursos de tecnologia assistiva no contexto da escolarização no ensino regular do aluno com paralisia cerebral mais comprometido motoramente a partir do ponto de vista do professor do aluno com deficiência física.

Considera-se que a percepçáo do professor a respeito do uso do recurso de tecnologia assistiva pode trazer informaçóes importantes e complementares em relação à forma que os recursos de tecnologia assistiva estão sendo implementados e utilizados no contexto escolar.

\section{Métodos}

Participaram deste estudo cinco professores de alunos com paralisia cerebral com nível motor IV e V segundo Classificação da Função Motora Grossa para paralisia cerebral - GMFCS (HIRATUKA; MATSUKURA, 2007).

Como o objetivo do estudo foi investigar o contexto da escolarização no ensino regular do aluno com paralisia cerebral mais comprometido motoramente, utilizou-se o sistema de Classificação da Função Motora Grossa - GMFCS adaptado para o português por Hiratuka e Matsukura (2007) para a seleção dos alunos inicialmente. Nesse instrumento, a diferença entre os níveis de classificação proposta é permeada pelas limitaçóes funcionais, pela necessidade de tecnologia assistiva para mobilidade e, em uma extensão menor, pela qualidade do movimento. Os níveis IV e V são os que correspondem às maiores limitaçóes funcionais e que necessitam de mais recursos de tecnologia assistiva.

Para a seleção dos professores potenciais, primeiramente foram selecionados os alunos. Estes deveriam frequentar o ensino fundamental de escola regular e fazer uso, há pelo menos seis meses, de recurso de tecnologia assistiva que os auxiliassem na execução de tarefas de escrita e/ou comunicaçáo. Estabelecidos estes critérios, foram encontrados, via secretária de Educação Especial de dois municípios do interior do estado de São Paulo (um de grande e outro de médio porte), cinco crianças potenciais e seus respectivos professores, sendo estes últimos o foco desta pesquisa.

O professor foi convidado a participar da pesquisa após conhecer os objetivos do estudo e solicitado a assinar o termo de consentimento livre e esclarecido.

Em relação à caracterização dos professores, o tempo de experiência profissional como professor variou de 8 a 43 anos, e o tempo de experiência profissional com educação especial variou de 1 a 25 anos. Apenas uma professora informou ter realizado curso de capacitação em educação especial oferecido pelo Estado.

Os recursos de tecnologia assistiva utilizados pelas crianças foram: lápis engrossado, tarefas adaptadas, cadeiras de rodas, mesa adaptada, tarefa xerocada, escriba, pulseira de chumbo, molde vazado, tesoura adaptada, letras móveis e tabuleiro e prancha de comunicação. O tempo de uso dos recursos de tecnologia assistiva variou de 8 meses a 3 anos.

Como instrumentos de coleta de dados, além do GMFCS, foi utilizado um roteiro de entrevista semiestruturado que buscou focalizar a percepção do professor sobre o recurso de tecnologia assistiva utilizado pela criança em sala de aula. $\mathrm{O}$ roteiro de entrevista focalizou quatro temas: a) tecnologia assistiva (investiga características do recurso como facilidade de uso, dificuldades, forma de prescrição, orientaçóes recebidas, participação na escolha, etc.); b) tarefas de sala de aula (como é feita a tarefa, contribuiçóes e dificuldades que o recurso oferece e outros); c) socialização (interação do aluno, como se comunica, estratégias utilizadas para a comunicação); e d) escolarização e recurso de tecnologia assistiva (contribuiçôes e dificuldades trazidas pelos recursos de tecnologia assistiva para a escolarização do aluno na escola comum e como 
a escolarização do aluno com deficiência física é percebida).

Para a validação do roteiro, este foi enviado a três juízes com experiência mínima de três anos na área de tecnologia assistiva e educação especial.

A aplicação da entrevista com os professores foi registrada através de um gravador de áudio. As entrevistas coletadas foram transcritas na íntegra e apresentadas aos mesmos para que pudessem lê-las e validá-las.

Os dados obtidos pelas entrevistas dos professores foram analisados a partir da técnica do Discurso do Sujeito Coletivo (DSC) (LEFĖVERE; LEFĖVERE, 2005). A técnica consiste em reconstruir, com trechos de discursos individuais, discursos-síntese que expressem uma dada figura ou representação social sobre um fenômeno. Primeiramente, cada questão foi analisada isoladamente a partir das respostas de todos os sujeitos. Foram identificadas expressôes- chave, obedecendo a uma esquematização clássica de começo, meio e fim ou do mais geral para o mais especifico, eliminando-se repetições de ideias, particularidades como sexo, doenças e outros. Estas foram agrupadas de acordo com o tema comum criando-se denominaçôes para cada agrupamento, a ideia central. A ideia central é a maneira mais sintética, precisa e fidedigna possível que descreve o sentido de cada um dos discursos analisados. Elaborou-se um DSC para cada ideia central. Segundo esse tipo de análise, os resultados podem ser apresentados por questáo ou com um quadro-síntese. Optou-se em apresentar o DSC dos cuidadores de acordo com a sequência das questóes feitas a eles na entrevista.

\section{Resultados}

A seguir serão apresentados os principais resultados advindos das entrevistas com os professores.

\section{Questáo 1: Quais sáo os recursos de tecnologia assistiva que o aluno utiliza em sala de aula?}

Com relaçấo aos recursos de tecnologia assistiva que as crianças utilizam em sala de aula foram identificadas duas ideias centrais e, portanto, dois DSCs foram gerados.

Ideia central 1: Descrição dos professores a respeito dos recursos utilizados e o porquê do uso.

DSC 1:

A única coisa que eu uso é um lápis que a gente fez a adaptação, engrossou o lápis, para ficar melhor na mão dela porque ela não tem a coordenação. [...] ele tinha a escriba agora ... eu passo a lição, termina, tira um xérox do caderno do colega e ele leva para casa.[...] ele tem as adaptaçóes dele tipo uma pulseirinha que ele fez com peso de chumbinho que, como ele náo tem firmeza na mão, então essa pulseirinha é para pesar na mão para ele ter força para ele poder fazer, o terapeuta ocupacional adaptou um sistema, um papelão onde tinha uma parte vazada que era para o aluno tentar escrever dentro dessa margem vazada e a colher [...] uma lousinha de velcro, para estar trabalhando com ele e o alfabeto móvel que também veio junto com esse material. [...] Os textos que a professora da sala de recurso amplia, ela colhe o material da sala de aula, a tarefa que eu estou fazendo no momento, faz a adaptação com a letra ampliada e eu trabalho com ela. Esses materiais são feitos de acordo com a proposta $d a$ atividade da minha sala.

Ideia central 2: Professores descrevem sobre recursos humanos.

DSC 2:

No primeiro semestre tinha uma estagiária... coloquei ela mais assim, para acompanhar ele, a pessoa dava uma ajuda para ele, quando era para ler um texto ela lia para ele o texto, chegava na hora de assinalar, ela fazia a pergunta para ele e ele respondia da maneira que ele estava entendendo, ela também procurava fazer ele entender e ai ele respondia e ela assinalava para ele, mas o que eu acho é assim, não que eu acho que não foi válido... mas o que eu não concordava muito porque ele se tornava muito dependente dela, então isso acabava se tornando não inclusivo e ele ficava fora. [...] Tinha uma estagiária na sala que cuidava assim, dessa parte de ficar com ele sob minha orientação e em alguns momentos eu também acompanhava junto com ele esse trabalho. [...] Eu recebi a orientação da secretaria da educação para estar trabalhando com escriba, então cada dia ele senta com um amigo e dai das atividades do dia a gente vê, passa uma e ele vai respondendo oralmente $\mathrm{e}$ o amigo vai fazendo o registro para ele. [...] A estagiária de Pedagogia tem ficado com ela, antes era a professora da sala de recurso mais no sentido de dar um suporte, de acelerar esse processo da adaptação da atividade.

No primeiro DSC observa-se a descrição dos professores sobre os recursos que o aluno utiliza atualmente e sua finalidade. No segundo DSC os professores apresentam a descrição de outros tipos de apoio dado ao aluno como a presença de outros profissionais em sala de aula e do auxílio dos colegas de turma e falam sobre o efeito desse apoio. 
Questáo 2: Esses recursos auxiliam o aluno? Em quê?

Em relação ao auxílio que o recurso de tecnologia assistiva traz, foram gerados dois DSCs.

Ideia central 1: Auxiliam, porém alguns fatores interferem no nível de auxílio.

\section{DSC 1:}

Auxiliam, tanto é que ela está alfabetizada, né, auxilia na alfabetização dela, na aprendizagem. [...] Eu acho que ajuda sim desde que ele tenha todos os recursos. [...] Olha, eu vejo assim, que auxilia sim, mas como não teve uma receptividade por parte dele, ainda a gente conversando, insistindo, tudo, então acabou que não foi muito bem aproveitado né? [...] Auxiliam. Porque ela consegue acompanhar a turma, isso fica muito claro. E acaba tirando aquela ansiedade, né, $e$ a ansiedade do professor porque o professor se sente incapaz.

Ideia central 2: Não auxiliam.

\section{DSC 2:}

"Não. Ajudaria a continuação da escrita."

O primeiro DSC apresenta o recurso de tecnologia assistiva como auxiliar ao aluno, porém os professores apresentam outros fatores que interferem no nível de auxílio que o recurso traz como a necessidade de aquisição de todos os recursos necessários e a aceitação do aluno. O segundo DSC mostra que o recurso utilizado atualmente não auxilia o aluno e que o utilizado anteriormente trazia maior beneficio ao aluno.

Questáo 3: Esses recursos trazem alguma dificuldade para o aluno? Em quê?

A partir dessa questáo foram gerados dois DSCs.

Ideia central 1: $\mathrm{O}$ recurso de tecnologia não traz dificuldades ao aluno.

\section{DSC 1:}

"[...] Tem que fazer desse jeito ou ficar junto atendendo com ela individualmente e é um tempo que o professor não tem. [...] Não trazem dificuldades, pelo contrário."

Ideia central 2: $\mathrm{O}$ recurso traz dificuldades ao aluno.

\section{DSC 2:}

No xérox é o seguinte, ele não tem motivação de ficar prestando atenção, ele sabe que geralmente pega o caderno do melhor aluno, está tudo pronto e com a escriba ela fazia ele pensar, então ele tinha que tentar resolver. A escriba era bem melhor. [...] Eu acho que quando náo tem o recurso devido para criança a gente acaba que por improvisar $e$ aí aquilo não está adequado para criança e a criança se sente na dependência, se sente realmente uma criança especial [...] às vezes eu tenho a impressão que ele fica se sentindo assim mais diferente ainda. $O$ recurso reforça.

Questáo 4: Como foram indicados ou criados os recursos de tecnologia que o aluno utiliza?

Quanto à forma de indicaçáo do recurso de tecnologia assistiva dois DSCs foram gerados.

Ideia central 1: $O$ recurso de tecnologia assistiva foi elaborado pelo próprio professor.

DSC 1:

"Foi minha experiência do dia a dia."

Ideia central 2: Pelos órgãos de educação e terapeutas.

\section{DSC 2:}

Foi a secretaria que mandou... pela secretaria da educação mesmo. [...] Os recursos foram com a ajuda do terapeuta ocupacional, da colher foi o terapeuta, ele assim trouxe assim, muita coisa que enriqueceu muito... ele fez essa parte vazada e nós copiamos num papel mais duro porque o que ele fez foi num papel mole e entortava, então fizemos num papel mais durinho.[...] A prancha já existia quando o aluno veio para escola, feita no centro de reabilitação.

O primeiro DSC mostra a participação do professor na elaboração do recurso de tecnologia assistiva e o segundo DSC refere à participaçáo de órgãos da educação e terapeutas na elaboração e indicação do recurso.

Questáo 5: Você recebeu orientaçáo sobre o uso do recurso de tecnologia assistiva ou fez algum curso de capacitaçáo?

Em relação à orientação ou capacitação dos professores para o uso do recurso de tecnologia assistiva, dois DSCs foram criados.

Ideia central 1: Os professores não receberam orientaçóes sobre o recurso.

\section{DSC 1:}

Não, não recebi orientação nenhuma. [...] Veio a moça da secretaria encarregada, conversou com ele e disse que seria assim. E a coordenadora veio para mim e disse que seria assim. Porque assim as ordens sấo todas vindas de cima para baixo, nunca perguntam para o aluno e nem para o professor o que é bom para eles.

Ideia central 2: Receberam orientações da equipe de reabilitaçáo e/ou da secretaria de educaçáo especial e profissionais da educação especial. 


\section{DSC 2:}

O terapeuta ocupacional passou para mim... ele me deu muita orientaçâo, tanto para mim como para mãe, para mãe também, porque a máe fica o tempo todinho com o aluno na sala de aula, então tanto para mim quanto para mãe e foi ótimo. [...] Recebi orientação delas, no começo do ano veio uma pedagoga e ai depois veio a terapeuta ocupacional. Mas demorou um pouquinho para elas virem, tive que insistir muito, para coordenação, para direção, para eu saber o que fazer com ele porque até então eu tava sem saber como agir mesmo. [...] A professora da sala de recurso me orienta, mas náo existe um momento especifico. No dia a dia a gente vai tentando introduzir esses conceitos, como usar os recursos.

No primeiro DSC diz respeito à falta de orientação dada aos professores quanto ao recurso utilizado e no segundo mostra que a orientação ao professor quanto ao uso do recurso foi dada por profissionais da área como secretária de educação especial, terapeutas e professores da sala de recurso.

Questáo 6: Em sua opiniáo, o que o recurso deve ter para ser considerado um bom recurso para seu aluno?

A questấo possibilitou a construção de dois DSCs.

Ideia central 1: Professores descrevem a praticidade, especificidade e ser um recurso atrativo como características de um bom recurso de tecnologia assistiva.

\section{DSC 1:}

Tem que ser prático porque ele não tem coordenação, tem que ser uma coisa bem prática. [...] Olha, eu acho que tem que adaptar de acordo com as necessidades do aluno especial. Então ver quais as dificuldades dele e ter todo o material. [...] Eu acho que tem que ser muito atrativo para ele, para ele esquecer um pouco essa questão do lápis, que é muito forte para ele, sabe, ficar o lápis ali tentando escrever. Acho que tem que ser alguma coisa bem diferente, por isso que eu pensei no computador, né? Ele tem que ser visualmente chamativo, tem que ser uma coisa com um tamanho bom, uma cor chamativa.

Ideia central 2: Não souberam responder.

\section{DSC 2:}

"Não sei."

No primeiro DSC é feita a descrição de diferentes características atribuídas a um recurso de tecnologia eficiente ao aluno como praticidade, especificidade e a necessidade de ser um recurso atrativo. Já no segundo DSC os professores não souberam responder a questão.

Questão 7: Você acha que o aluno necessitaria de outros recursos? Quais?

Em relação à necessidade de novos recursos de tecnologia assistiva ao aluno foi possível gerar três DSC.

Ideia central 1: Professores sugerem o computador adaptado como outro recurso possível.

\section{DSC 1:}

[...] Ela teria que ter um computador adaptado à deficiência, à limitação dela. [...] O computador, né, e que ele fosse adaptado, que o teclado teria que ser... com o computador ela náo ia depender de ninguém, ela mesma faria o trabalho dela sozinha. [...] Eu gostaria muito de poder ter um recurso para ela usar o computador. Um acionador, alguma coisa que ela pudesse tocar ali a mãozinha ou um toque de cabeça pra ela experimentar coisas novas.

Ideia central 2: Não souberam responder.

\section{DSC 2:}

Não imagino o que seria porque é a primeira vez que eu estou lidando com esse tipo de criança. Inclusive a secretária disse que colocaria um computador para ela, mas eu acho que o computador não é ainda viável para esse tipo de criança porque ela não tem a coordenação para mexer no mouse, então eu acho que criou expectativa nela, mas ela ficaria limitada, ela veria que não ia conseguir.

Ideia central 3: Náo necessitam de recurso e sim de um profissional especializado.

DSC 3:

Acho que assim, seria um acompanhamento individualizado mesmo porque é difícil você ficar com uma sala inteira. O C4 tem uma defasagem muito grande na alfabetização, ai tem toda uma cobrança em cima disso e ele também, que ele também precisa. O computador eu acho que de repente na aula de informática, se tivesse, porque assim seria um momento que ele estaria junto com todos, né, para aula de informática, e assim, estando junto com todo mundo, mas voltado para ele, individualizado.

No primeiro DSC os professores sugerem o uso do computador adaptado às necessidades do aluno, no segundo DSC os professores não conseguiram responder a essa questão e no terceiro DSC os professores sugerem o apoio individualizado ao aluno. 
Questáo 8: $\mathrm{O}$ recurso de tecnologia assistiva auxilia o aluno a executar alguma tarefa de sala de aula? Qual? Como?

Dois DSCs foram feitos sobre o nível auxílio trazido pelo recurso de tecnologia assistiva na execução das tarefas.

Ideia central 1: A tecnologia assistiva auxilia o aluno a executar a tarefa, e justificam.

\section{DSC 1:}

Ajuda a fazer textinhos, ela consegue escrever. [...] Eu acho que as adaptaçôes seriam o conhecimento para ele. Eu acho que ele poderia aprender a ler eo material adaptado ajudaria muito, ele aprenderia a ler, não precisaria de uma criança ou, que nem no caso, do estagiário... ele seria independente e outra, ele se valorizaria, autoestima, isso, uma vez que ele faz sozinho essas coisas. Eu acho que ele tem que aprender a se virar sozinho porque não vamos pensar no futuro, vamos pensar hoje nas adaptaçóes dele e ele melhorando cada dia mais. [...] As letrinhas móveis ajudam porque, assim, a gente está sempre reforçando que tem outras formas de escrever que não só com o lápis. [...] Ajuda... ela faz.

Ideia central 2: Professores referem que o recurso atual não auxilia o aluno na execução da tarefa, $\mathrm{e}$ justificaram.

\section{DSC 2:}

Não. Pelo contrário porque ele pode sair e a criança está com a lição pronta para ele. $\mathrm{Na}$ escrita não, ele tinha que ficar. Para ele está bom, eu como professora não está, para ele está cômodo isso porque ele não precisa mais pensar. [...] Ele não aceita o recurso.

O primeiro DSC descreve que o recurso de tecnologia auxiliava a execução de tarefas como escrita, leitura, repercutindo na independência e autoestima do aluno. O segundo DSC mostra que, na opiniáo do professor, o recurso de tecnologia assistiva utilizado traz limitaçóes ao aluno na execução da tarefa.

\section{Questáo 9: Você entende o que o aluno quer lhe contar?}

Em relação à compreensão que o professor tem do aluno dois DSCs foram feitos.

Ideia central 1: Professores referem compreender o que o aluno quer comunicar.

DSC 1:

Entendo tudo, ele fala, ele briga, com os amigos também. [...] Entendo tudo. [...] Entendo, assim dependendo da conversa que eu estou tendo com ele, eu tenho que me aproximar dele mais, olhar bastante na boquinha dele, mas no geral dá pra entender. [...] Assim, nos primeiros dias, você sente um pouco mais de dificuldade de entender o que ele fala, mas depois você se habitua e dá pra entender bem.

Ideia central 2: Professores referem compreender parcialmente o que o aluno quer comunicar.

\section{DSC 2:}

"Muitas vezes sim, às vezes não, aí eu chamo alguém porque se eu fico insistindo ela fica nervosa. [...] Às vezes, às vezes ela fica ansiosa e não dá."

No primeiro DSC os professores referem entender o aluno e no segundo DSC os professores referem compreender parcialmente.

Questáo 10: Os recursos de tecnologia assistiva trouxeram alguma contribuiçáo ao processo de inclusão do aluno? Qual?

Sobre a contribuição trazida pelo recurso de tecnologia assistiva ao processo de inclusão escolar dois DSCs foram elaborados.

Ideia central 1: $\mathrm{O}$ recurso de tecnologia contribuiu no processo de inclusão.

DSC 1:

Ajudou bastante, para ele conseguir a aprendizagem. Porque sem isso seria muito mais difícil, não teria como. [...] Não teria como ele participar da escola porque ele ficaria só ouvindo, não teria como, ele é uma criança, ficar só ouvindo, ouvindo. [...] Ajuda muito. Ainda é muito pouco, mas tem ajudado. Se fosse mais cedo teria auxiliado mais. [...] A baixa tecnologia auxilia muito primeiro porque é um material de qualidade e eles acabam melhorando a aprendizagem.

Ideia central 2: $\mathrm{O}$ recurso de tecnologia assistiva não trouxe contribuiçáo à inclusão do aluno.

DSC 2:

Não, eu acho que não. Eu acho que a presença dele na escola independe porque esses recursos vieram esse ano e esse já é o segundo ano dele aqui na escola. Então esses materiais não existiam e ele deu conta, ele responde tudo.

O primeiro DSC apresentou a opiniáo dos professores em relação às contribuiçôes que o recurso de tecnologia assistiva trouxe à inclusão do aluno como auxílio à aprendizagem e na participaçáo do aluno. No segundo DSC os professores referiram que o recurso náo contribuiu com o processo de inclusão da criança-alvo. 


\section{Discussão}

\subsection{Sobre os recursos de tecnologia assistiva}

Considerando-se os resultados obtidos nas entrevistas com os professores, observa-se que os mesmos descreveram como recursos de tecnologia assistiva materiais adaptados, tarefas adaptadas e recursos humanos como estagiárias e escriba.

Dessa forma a tecnologia pode ser vista como recursos amplos assim como descrito pelo Comitê de Ajudas Técnicas - Secretaria Especial dos Direitos Humanos da Presidência da República, que define a tecnologia assistiva como

[...] produtos, recursos, metodologias, estratégias, práticas e serviços que objetivam promover a funcionalidade, relacionada à atividade e participação, de pessoas com deficiência, incapacidades ou mobilidade reduzida, visando sua autonomia, independência, qualidade de vida e inclusão social [...] (BRASIL, 2007).

Os recursos de tecnologia assistiva de baixo custo foram citados com maior frequência, o que pode indicar que esses recursos são os mais utilizados pelos alunos e/ou mais acessíveis ao contexto escolar atual.

A SEEP e o MEC têm disponibilizado aos professores materiais de apoio à escolarização da criança com deficiência física. Nestas publicaçóes nota-se a indicaçáo frequente de materiais adaptados como recursos auxiliares possíveis ao contexto escolar, como as letras ampliadas, lápis engrossados, moldes vazados, mobiliário adaptado e tarefas adaptadas (GODÓI; GALASSO; MIOSSO, 2002; SILVA; CASTRO; BRANCO, 2006; SCHINEMER et al., 2007; BRASIL, 2002; MANZINI; DELIBERATO, 2006).

No entanto, o DSC pode mostrar que, para os professores, o recurso de tecnologia pode também ter um papel reforçador à deficiência.

A partir desse DSC, é possível refletir sobre a compreensão dos professores acerca da inclusão e de como compreendem as diferenças neste contexto, parecendo ainda haver uma compreensão de inclusão que implica em uma referência uniformizadora. Em relaçấo a essa prática, Silva, Castro e Branco (2006) discutiram que uma prática uniformizadora vem comprometendo a pluralidade, anulando ou minimizando a importância do respeito à diversidade e, dessa forma, desconsiderando as peculiaridades dos alunos com necessidades educacionais especiais.
Considera-se que tais achados reforçam a necessidade de continuidade de discussóes e reflexóes com os principais atores envolvidos nesse processo acerca do significado e das possibilidades concretas da inclusão escolar.

Os professores relataram que a prescrição e a indicação dos recursos de tecnologia assistiva foram feitas por profissionais da Secretaria de Educaçáo Especial, terapeutas ocupacionais e professores, assim como as orientaçóes periódicas.

Mesmo contando com a supervisão de técnicos/ especialista, nota-se que a indicação e implementação dos recursos de tecnologia assistiva e de tarefas adaptadas ainda estáo sendo feitas sem a efetivação de parcerias entre os envolvidos no processo: profissionais de educação especial, profissionais da reabilitação, aluno, professores e família.

Outro fator crítico, segundo Mello (2006), é o desconhecimento técnico que ainda existe entre os profissionais de reabilitação e a falta treinamento específico para que os profissionais de reabilitaçáo se tornem provedores de tecnologia assistiva. Algumas alternativas desenvolvidas nos últimos anos por profissionais em todo o país são os cursos extracurriculares sobre o tema. Isso vem possibilitando que mais profissionais estejam capacitados para atender a demanda crescente.

Notou-se que dentre os profissionais que realizaram prescriçóes e orientaçóes de recursos de tecnologia assistiva, o terapeuta ocupacional foi um dos profissionais citados. Toyoda (2008), ao discutir a formação de profissionais em tecnologia assistiva no âmbito nacional, refere que o ensino de tecnologias assistivas baixa, média ou alta esteve presente nos currículos de graduação de terapia ocupacional desde 1970 .

O Conselho Federal de Fisioterapia e Terapia Ocupacional $^{2}$ aponta como atos privativos $\mathrm{da}$ profissão: a) a análise da atividade, ou seja, é o profissional que analisa todos os aspectos da vida cotidiana de uma pessoa e as atividades devem ser previamente selecionadas, analisadas e adaptadas de forma individualizada; b) atendimento de atividades de vida diária (AVDs) que dizem respeito ao cuidado de si próprio e da sua comunicação; e c) uso de adaptaçóes e dispositivos como recursos que facilitem a realização das atividades, promovendo a independência pessoal e a melhora da funcionalidade e a qualidade de vida, cabendo ao terapeuta ocupacional planejar, prescrever, confeccionar, orientar e treinar.

Segundo Pelosi (2005), o terapeuta ocupacional, conforme sua especialidade, foca o uso da tecnologia 
na função, ou seja, na habilidade de realizar tarefas específicas em casa, na escola ou no ambiente de lazer.

Para isso, o terapeuta ocupacional utiliza recursos próprios da profissão como a análise do contexto, do desempenho, da tarefa e de seus componentes para avaliar, propor e acompanhar o uso de recursos de tecnologia assistiva de acordo com as demandas dos usuários.

Sabe-se que devido às demandas trazidas pela inclusão do deficiente, atualmente outros cursos de graduação já estão focados na capacitação de profissionais para a promoção de tecnologia assistiva como os de fisioterapia, fonoaudiologia, engenharia e educação. Como já discutido, nota-se que a formação de profissionais em tecnologia assistiva vem expandindo-se, ainda que de forma lenta, através dos cursos de graduação, reformulaçóes curriculares de cursos de formação superior de educadores e profissionais de reabilitação, de cursos de especialização interdisciplinares, cursos de pós-graduação específicos, projetos e grupos de pesquisas.

Os resultados das entrevistas com os professores mostraram também que o acesso ao recurso de tecnologia assistiva e ao processo de adaptação deveria ocorrer no momento em que o aluno é inserido na escola regular. Não obstante, nota-se que os professores têm buscado auxílio, porém o apoio acontece de forma lenta, o que faz com que professores e familiares criem suas próprias estratégias.

Vale ressaltar que a criação de estratégias e/ou o desenvolvimento de recursos por professores e familiares podem ser positivos, porém não quando utilizados de forma solitária e/ou em tentativas aleatórias. Tem-se como hipótese que a demora ao acesso para esse tipo de serviço pode levar ao uso incorreto de métodos e recursos que acabam por prejudicar ou adiar o bom desempenho do aluno.

É possível verificar no DSC que alguns critérios foram citados pelos professores para que o recurso de tecnologia assistiva seja considerado eficiente, como a praticidade, especificidade, interesse e motivação do usuário, assim como mostrou o estudo de Scherer et al. (2005).

Parece que os professores, devido a suas experiências e práticas, têm a percepção adequada sobre critérios necessários a um recurso de tecnologia assistiva eficiente. Esses resultados reforçam os estudos que mostram que a eficiência do recurso não se deve somente à presença dos recursos assistivos em sala de aula, já que os professores consideraram fatores como os resultados trazidos ao usuário e seu contexto.
O uso do computador adaptado foi apontado por alguns professores como um possível recurso a ser utilizado pelos alunos. Considera-se que o acesso ao computador, quando direcionado à educação de crianças com deficiência física, torna-se mais específico, pois o computador necessitará de adaptaçóes direcionadas à demanda de cada aluno e, como qualquer outro recurso de tecnologia assistiva, necessitará também de treinamento e acompanhamento profissional especializado contínuo.

O computador na realidade escolar atual ainda tem sido disponibilizado ao aluno com deficiência física mais facilmente em contextos clínicos ou através de projetos extraescolares e salas especiais, os quais muitas vezes funcionam de forma complementar ao currículo do aluno, mas fora de sala de aula (PANHAN, 2001; BORGES; WATANABE, 2001; OLIVEIRA, 2002; LOURENÇO; MORAIS; MENDES, 2008).

Considera-se que tentativas estão sendo feitas, como pode ser visto nos estudos aqui apresentados, porém nota-se que os projetos direcionados ao uso da alta tecnologia na escola ainda não contemplam a sala regular.

Deve-se ressaltar também que, para o computador exercer um papel auxiliar à inclusão do aluno, ele deve estar dentro da sala para que assim promova a independência na escrita ou comunicação no momento de aula, contribuindo com o processo de aprendizagem dentro de seu contexto escolar. Além disso, o computador deve estar aliado a outros recursos assistivos, sejam eles de alto ou baixo custo, para que o aluno tenha mais de uma possibilidade de executar suas tarefas (GODÓI; GALASSO; MIOSSO, 2002; SILVA; CASTRO; BRANCO, 2006; SCHINEMER et al., 2007; BRASIL, 2002; MANZINI; DELIBERATO, 2006; BERSCH; PELOSI, 2007).

\subsection{A tecnologia e a execução de tarefas de sala de aula pelos alunos}

Neste estudo, os professores consideraram o recurso de tecnologia assistiva como um recurso auxiliar à execução das tarefas, principalmente por favorecer a produçáo do aluno levando, consequentemente, a influências positivas no âmbito emocional como autoestima e autonomia.

Os resultados deste estudo reforçam o estudo de Pelosi (2003), que aponta que o uso do recurso de tecnologia assistiva, no contexto escolar, permite que a criança não seja excluída das atividades e, 
principalmente, que não seja excluída do processo de aprendizagem porque não é capaz de escrever.

Nesta pesquisa notou-se que, na percepção do professor, o uso do recurso de tecnologia assistiva está ligado diretamente à produção e maneira de demonstrar conhecimentos. Isso deve ser considerado com cautela, pois como apontaram Rocha, Castiglioni e Vieira (2001), os recursos tecnológicos não são em si nem facilitadores nem dificultadores de processos de inclusão, táo pouco promotores de independência e autonomia. A utilização dos recursos deve ser discutida em relação à qualidade de inclusão que promove e para isso deve estar contextualizada em questôes como as individualidades, políticas e satisfação do cliente.

\subsection{A comunicação em sala de aula}

Observou-se pelo DSC dos professores que houve dificuldades na comunicação entre o aluno e o professor. Apesar da maioria dos alunos ter a fala como principal meio de expressão, a compreensão desta fala nem sempre é efetiva. Os professores referem que não há problema na comunicação, porém buscam estratégias como a leitura labial, o auxílio de um colega ou mesmo de recursos de comunicação alternativa.

Von Tetzchner et al. (2005) discutiram as bases teóricas do desenvolvimento de linguagem de formas alternativas e descreveram algumas estratégias que têm sido utilizadas para melhorar o ambiente linguístico das crianças que utilizam comunicação manual e gráfica no contexto da pré-escola regular. Os autores referiram que as modalidades de comunicação alternativa precisam se tornar parte da comunicação cotidiana na sala de aula. Referiram também que o meio partilhado de comunicação é um pré-requisito necessário para a interação entre crianças que utilizam comunicação alternativa e seus pares falantes, e isso pode ser conseguido de forma mais eficiente em contextos inclusivos.

Pelosi (2003) mostrou em seu estudo que as dificuldades de comunicação oral abrangem quadros bastante diversos, que vão desde a fala de difícil compreensão até sua ausência total. Dificuldades tão diversas necessitam soluçóes particulares que podem utilizar recursos de baixa ou alta tecnologia, dependendo das características da criança e do que ela precisa comunicar. Ainda referiu que as deficiências de comunicação receptiva e expressiva têm um enorme impacto sobre a atuação de um aluno. Os resultados de avaliaçóes formais e informais podem ser comprometidos porque um aluno pode ter capacidade limitada ou incapacidade para demonstrar a extensáo do seu conhecimento ou de suas habilidades.

Neste estudo, a dificuldade dos alunos na comunicação pareceu náo ser tão relevante ao professor quanto a sua produçáo em sala de aula. Porém, recursos assistivos de comunicação também devem fazer parte do cotidiano do aluno com dificuldade na fala, seja através dos recursos alternativos de comunicação, auxiliando a criança que não fala, ou dos recursos suplementares, contribuindo com os alunos de fala de difícil compreensão. Assim, o aluno poderá ter mais elementos para demonstrar seus conhecimentos e opiniōes, e o professor mais recursos para compreender seu aluno, conscientizando-se de que a comunicação é uma via de extrema importância que deve ser explorada.

\subsection{A tecnologia assistiva e o processo de escolarização dos alunos com deficiência física}

Os professores entrevistados afirmaram que o recurso de tecnologia assistiva auxilia a criança no processo de escolarização, pois seria inviável a participação do aluno com deficiência motora grave na escola sem o recurso, acrescentando que a tecnologia assistiva traria maiores benefícios se fosse implementada mais cedo.

Os dados do Censo Escolar de 2010 (BRASIL, 2011) mostraram a efetivação da Educação Inclusiva e o empenho das redes de ensino em organizar uma política pública universal e acessível às pessoas com deficiência. Os dados apontaram que o investimento do MEC vem aumentando, sendo em 2010 75,8\% do total de matrículas da educação especial estavam nas escolas públicas e $24,2 \%$ nas escolas privadas.

Porém, nota-se neste estudo que demandas como a dificuldade de acesso aos recursos de tecnologia assistiva e de outros recursos de apoio, seja para o professor ou para o aluno, ainda são mantidas observando-se que o acesso a esses recursos, muitas vezes, ainda dependem de iniciativas pessoais.

O DSC produzido através das falas dos professores confirmou os achados de Alpino (2003) em que os professores solicitaram o apoio especializado no processo de inclusão escolar mostrando que, para a facilitação da adaptação do aluno com paralisia cerebral na escola regular, há a necessidade de adequação do mobiliário escolar, adaptações do espaço físico, dos recursos e dos materiais pedagógicos utilizados pelos alunos.

Nesse sentido, ainda que haja investimentos de políticas públicas, os mesmos não estão suprindo a 
demanda atual que o sistema escolar necessita. Isso compromete os preceitos da inclusão escolar, que tem como foco a mudança na estruturação escolar para receber o aluno com deficiência. As práticas de escolarização da criança com paralisia cerebral observadas neste estudo parecem ainda estar em fase inicial de estruturação, embora seja visto que a introdução da política de inclusão no ensino municipal nas escolas pesquisadas iniciou-se entre os anos de 1997 e 2000.

\section{Considerações finais}

Os resultados puderam evidenciar a necessidade de considerar as opinióes e demandas dos envolvidos no contexto em que o recurso de tecnologia está inserido.

Os DSCs dos professores revelaram que os mesmos descreveram o recurso utilizado como útil nas tarefas de sala por favorecer a participação do aluno e o processo de avaliação pedagógica. Alguns professores receberam orientaçôes quanto ao uso do recurso, porém não participaram do processo de implementação e escolha deste. A maior parte dos entrevistados referiu a necessidade de mais suporte tanto para o aluno quanto para o professor.

Este estudo pode contribuir para maior compreensão sobre o tema, porém novas pesquisas devem ser direcionadas a essa área, visto que há um crescente aumento na demanda e na promoçáo de recursos de tecnologia.

Alguns desafios ainda permeiam esse contexto, como a ausência do trabalho conjunto entre educação especial, professor, equipe de reabilitação, administradores, aluno e família, como tem apontado a literatura. Portanto, nota-se que as práticas que valorizam e aliam os potenciais de seus participantes, como a implementação de trabalho em equipe, a participação de equipes itinerantes no suporte escolar e a capacitaçáo dos profissionais envolvidos, podem mostrar bons resultados nesse contexto.

\section{Referências}

ALPINO, A. M. S. O aluno com paralisia cerebral no ensino regular: ator ou expectador do processo educacional? 2003. 141 f. Dissertaçáo (Mestrado em (Educacao do Individuo Especial)-Centro de Educação e Ciências Humanas, Universidade Federal de São Carlos, São Carlos, 2003.

ARAÚJO, R. C. T.; OMOTE, S. Atribuição de gravidade motora à deficiência física em funçáo da extensão do acometimento e do contexto escolar. Revista Brasileira de Educação Especial, Marília, v. 11, n. 2, p. 241-254, maio/ago. 2005. http://dx.doi.org/10.1590/ S1413-65382005000200006

BERSCH, R. C. R.; PELOSI, M. B. Portal de ajudas técnicas para a educação: equipamento e material pedagógico para a educação, capacitação e recreação da pessoa com deficiência física: tecnologia assistiva: recursos de acessibilidade ao computador. Brasília: Secretaria de Educação Especial, 2007.

BORGES, J. A.; WATANABE, M. K. Teclado Amigo: um sistema para acesso alternativo a computadores para portadores de deficiências motoras severas. Temas sobre desenvolvimento, São Paulo, v. 58, n. 10, p. 43-50, 2001.

BRASIL. Ministério da Educação e Cultura. Resumo técnico - Censo Escolar 2010. Brasília: Secretaria de Educaçáo Especial, 2011. Disponível em: <http://portal.mec.gov.br/ index.php?option=com_content\&view=article\&id=16179>. Acesso em: 18 jun. 2011.

BRASIL. Subsecretaria Nacional de Promoção dos Direitos da Pessoa com Deficiência - CORDE. Comitê de ajudas técnicas. Brasília: CORDE, 2007. Disponível em: <http://portal.mj.gov.br/corde>. Acesso em: 29 set. 2010.

BRASIL. Ministério da Educação e Cultura. Portal de ajudas técnicas para educação: equipamento e material pedagógico para educação, capacitação e recreação da pessoa com deficiência física: recursos pedagógicos adaptados. Brasília: Secretaria de Educação Especial, 2002. Disponível em: <http://portal.mec.gov.br/seesp/index. php?option=content\&task=view\&id=157\&Itemid=309> . Acesso em: 19 jul. 2010.

BROWNING, N. O desenvolvimento das aptidōes literárias da criança com deficiência física. Temas sobre desenvolvimento, São Paulo, v. 11, n. 64, p. 35-41, 2002.

COPLEY, J.; ZIVIANI, J. Barriers to the use of assistive technology for children with multiple disabilities. Occupational Therapy International, Singapore, v. 11, n. 4, p. 229-43, 2004. http://dx.doi.org/10.1002/oti.213 GODÓI, A. M.; GALASSO, R.; MIOSSO, S. M. P. Educação infantil: saberes e práticas da inclusãodificuldades de comunicação e sinalização - deficiência física. Brasília: Secretaria de Educação Especial, 2002. Disponível em: <http://portal.mec.gov.br/seesp/index. php?option $=$ content\&task $=$ view\&id $=87 \&$ Itemid $=216>$. Acesso em: 06 jul. 2010.

GOMES, C.; BARBOSA, A. J. G. Inclusão escolar do portador de paralisia cerebral: atitudes de professores do ensino fundamental. Revista Brasileira de Educação Especial, Marília, v. 12, n. 1, p. 85-100, jan./abr. 2006. http://dx.doi.org/10.1590/S1413-65382006000100007 HIRATUKA, E.; MATSUKURA, T. S. Sistema de classificação da função motora grossa para paralisia cerebral GMFCS. McMaster University, 2007. [Documento online]. Disponível em: <http://motorgrowth.canchild. ca/en/GMFCS/resources/GMFCS_portuguese.pdf>. Acesso em: 27 jul. 2011.

LEFÈVERE, F.; LEFÈVERE, A. M. C. O Discurso do sujeito coletivo: um novo enfoque em pesquisa qualitativa (desdobramentos). Rio Grande do Sul: EdUCS, 2005. 
LOURENÇO, G. F.; MORAES, L. F. R.; MENDES, E. G. O uso da alta tecnologia assistiva como ferramenta complementar para a alfabetização de alunos com paralisia cerebral: a distância entre sala de recursos e sala comum. In: CONGRESSO BRASILEIRO DE EDUCAÇÃO ESPECIAL, 3.; ENCONTRO DA ASSOCIAÇÃO BRASILEIRA DE PESQUISADORES EM EDUCAÇÃO ESPECIAL, 4., 2008, São Carlos. Anais... São Carlos: UFSCar, 2008.

MANZINI, E. J.; DELIBERATO, D. Portal de ajudas técnicas para educaşão: equipamento e material pedagógico para educação, capacitação e recreação da pessoa com deficiência física: Recursos para comunicação alternativa. Brasília: Secretaria de Educação Especial, 2006. Disponível em <http://portal.mec.gov.br/seesp/index.php?option $=$ content\&task $=v i e w \& i d=157 \&$ Itemid $=309>$. Acesso em: 29 set. 2010.

MELLO, M. A. F. A Tecnologia Assistiva no Brasil. In: FÓRUM DE TECNOLOGIA ASSISTIVA E INCLUSÃO SOCIAL DA PESSOA DEFICIENTE, 1.; SIMPÓSIO PARAENSE DE PARALISIA CEREBRAL, 4., 2006, Belém. Anais... Belém: UFPA, 2006.

OLIVEIRA, A. I. A. Tecnologia Assistiva - Abordagem inovadora do terapeuta ocupacional. Revista Brasileira de Fisioterapia, São Carlos, n. 15, p. 18-23, 2002.

PANHAN, H. A tecnologia no espaço clínico e terapêutico fonoaudiológico. Temas sobre desenvolvimento, São Paulo, v. 10, n. 58, p. 55-58, 2001.

PELOSI, M. B. O papel do terapeuta ocupacional na tecnologia assistiva. Caderno de Terapia Ocupacional da UFSCar, São Carlos, v. 13, n. 1, p. 39-45, 2005.
PELOSI, M. B. A comunicação alternativa escrita: Comunicaçáo alternativa-favorecendo o desenvolvimento da comunicaçáo alternativa em crianças e jovens com necessidades educacionais especiais. Rio de Janeiro: Dunya, 2003.

ROCHA, E. F.; CASTIGLIONI, M. C.; VIEIRA, R. C. A inclusão da criança com deficiência na escola comum: reflexôes sobre o papel da terapia ocupacional. Revista de Terapia Ocupacional da Universidade de São Paulo, v. 12, n. 1-3, p. 8-14, 2001.

SCHERER, M. J. et al. Predictors of assistive technology use: The importance of personal and psychosocial factors. Disability and Rehabilitation, London, v. 27, n. 21, p. 1321-1331, 2005. http://dx.doi. org/10.1080/09638280500164800

SCHINEMER, C. R. et al. Atendimento educacional especializado: deficiência física. Brasília: Secretaria de Educação Especial, 2007.

SILVA, A. F.; CASTRO, A. L.; BRANCO, M. C. A inclusão escolar de alunos com necessidades educacionais especiais: deficiência Física. Brasília: Secretaria de Educaçáo Especial, 2006

TOYODA, C. Y. Formação em tecnologia assistiva. In: ENCONTRO DE TECNOLOGIA ASSISTIVA DA FACULDADE DE MEDICINA DE RIBEIRÃO PRETO-USP, 2008, Ribeirão Preto. Anais... Ribeirão Preto: USP, 2008.

VON TETZCHNER, S. et al. Inclusão de crianças em educação pré-escolar regular utilizando comunicação suplementar e alternativa. Revista Brasileira de Educação Especial, Marília, v. 11, n. 2, p. 151-184, maio/ago. 2005. http://dx.doi.org/10.1590/S1413-65382005000200002

\section{Contribuição dos Autores}

Ambas as autoras contribuíram com a concepção, realização do estudo e redação do manuscrito.

\section{Notas}

${ }^{1}$ Este estudo faz parte de uma pesquisa mais ampla intitulada "A tecnologia assistiva como recurso à inclusão escolar de crianças com paralisia cerebral". Aprovado pelo comitê de ética em pesquisa em seres humanos da Universidade Federal de São Carlos: Parecer no 279/2007.

${ }^{2}$ Conselho Federal de Fisioterapia e Terapia Ocupacional: disponível em: <http://www.coffito.org.br/conteudo/con_view. asp?secao $=52>$. Acesso em: mar. 2012. 